\title{
Effect of Interactive Computer Based and Traditional Instructor-Led Based Training of Basic Life Support Programs among Healthcare Providers
}

\author{
Hajra Sarwar ${ }^{1}$, Sana Sehar², Muhammad Afzal ${ }^{3}$, Syed Amir Gilanii ${ }^{4}$, Asif Hanif ${ }^{5}$, Muhammad Mahboob Alam ${ }^{6}$, Altaf Pervez Qasim ${ }^{7}$ \\ 1,2,3,4,5Lahore School of Nursing, University of Lahore-Pakistan, ${ }^{6}$ Department of Medicine, Abwa Medical College, Faisalabad-Pakistan, ${ }^{7}$ Department of Forensic Medicine, Abwa Medical \\ College, Faisalabad-Pakistan
}

\begin{abstract}
Background: Basic Life Support is a specialized training program which enables the healthcare workers to refresh their knowledge \& skills for having up-to-minute information in this regard. This life saving skill training is evolving with introduction of new technological advances in teaching of healthcare personnel. It is not possible for the trainers to remain isolated from using the new training methods of such life-saving emergency care. Therefore, it was necessary to evaluate the current methods for Basic Life Support training for nurses with interactive computer-based training. Objective: To evaluate the effects of interactive computer based training and traditional instructor-Led based training of (BLS) among nurses. Study Design: Crosssectional study. Settings \& Duration: Study was conducted in Lahore School of Nursing (LSN), University of Lahore for a period of nine months. Methodology: Eighty-four practicing nurses were enrolled in the study \& two interventional groups were made having forty-two practicing nurses in each group. One group was traditional and other was computer based. Information obtained directly from participants. Twenty-five multiple item questionnaire \& checklists were used according to the guidelines of American Heart Association. Data analyzed by using SPSS version 21. Results: The mean value of pre computer and pre traditional knowledge score was $9.26 \pm 3.891$ and $11 \pm 4.708$, with mean difference, $p$-value $=0.000(<0.05)$. The mean value of pre computer and post computer knowledge score was $9.26 \pm 3.891$ and $20.11 \pm 5.454$, with mean difference, $p$-value $=0.000$ $(<0.05)$. The mean value of pre traditional and post traditional knowledge score was $11.12 \pm 4.708$ and $22.76 \pm 2.216$, with mean difference, $p$-value= $0.000(<0.05)$. The mean value of Post computer and post Traditional knowledge score was $20.11 \pm 5.454$ and $22.76 \pm 2.216$, with mean difference, $p$-value $=0.011(<0.05)$. Conclusion: Both interventional groups were helpful for acquiring or improving the knowledge and skills of Basic Life Support but the traditional instructor-led based training programs were more effective than computer-based training program.
\end{abstract}

Keywords: Basic Life support, Tradition instructor-led based training, Computer based training, Nurses.

Corresponding Author

Submitted for Publication: 22-08-2019

Accepted for Publication: 08-09-2020

Hajra Sarwar, Lecturer, Lahore School of Nursing, University of Lahore, Lahore-Pakistan.

Email: hajirasarwer@gmail.com

Citation: Sarwar H, Sehar S, Afzal M, Gilani SA, Hanif A, Alam MM, Qasim AP. Effect of Interactive Computer Based and Traditional InstructorLed Based Training of Basic Life Support Programs among Healthcare Providers. APMC 2020;14(3):227-32.

DOI: 10.29054/APMC/2020.996

\section{INTRODUCTION}

In the teaching methods for training, there are different techniques like interactive Computer-Based and Traditional Instructor-led based trainings and of these two methods Traditional Instructor-led based training is an old method to educate but interactive Computer-Based training is advance and inexpensive method. ${ }^{1}$ Traditional education, known as back-to-basics or conventional education refers to longestablished customs that society has traditionally used in schools and being transferred from one generation to other. In interactive computer-based training, all the related materials are provided in their easier access. ${ }^{2}$

According to Benjamin et al, ${ }^{3}$ the higher incidences of cardiac arrests reported (around 209,000 cardiac arrests) in hospital admissions of United States. Cardiopulmonary Resuscitation (CPR) has a great importance in frequent human emergencies, including cardiac arrest \& choking. Basic Life Support (BLS) is important life-saving activity despite having lot of advances in treatment of cardiac arrest. ${ }^{4}$ it's a combination of oral resuscitation \& external cardiac massage intended to reestablish cardiac function and blood circulation. It requires expertise of doing correct (CPR), by nurses \& medical personals. ${ }^{5}$

Recognizing and responding to cardiac arrest is a highly stressful situation for nurses and medical staff. Inadequate proficiency \& competence about (CPR) among nurses \& medics are well documented in literature. ${ }^{6}$ Nurses are frontline healthcare force responsible to recognize and act in case of sudden cardiac arrest. A study conducted by Asaadi et al 7 pointed out the importance of training for nurses to make them competent whereas other studies also highlighted multiple methods for learning of candidates about Basic Life Support i.e. Pre-reading materials \& incorporating a pre-test into the preparatory work. It was rated as improving their understanding but failed to show superiority for cognitive or psychomotor skills during a standard cardiac arrest simulation..$^{5-8}$ other option considered good compared to alone practice offering traditional BLS programs. Practice among trainee groups can be established through a hypothesis and training test frequently to decide if BLS preparing programs are proficient. ${ }^{9}$

Interactive compact disc-based training program facilitate to follow classroom learning through practical images of scenario, real time videos, and animated ECG graphics while Traditional 
instructor-led based program starts with use of manikins for routine practice of Basic Life Support. BLS Videos also appear to improve skill competence and retention when used within Traditional instructor-led programs. ${ }^{10}$ There are lots of ways to educate the learner to train in BLS, but here is need to reinforce the healthcare workers to retain knowledge and skills. Specific and important skills / guidelines for BLS procedure need to be used for training of nursing staff.

The estimated deaths due to cardiac arrest in Pakistan have reached up to 200,000 every year. ${ }^{11}$ According to a National Survival Report for emergency medical services-treated nontraumatic cardiac arrest, the survival rate to hospital discharge was $10.6 \%$ for adults $>18$ years old, $23.5 \%$ for children 13 to 18 years old, $16.6 \%$ for children $>1$ to 12 years old, and $6.2 \%$ for children $<1$-year-old. Approximately $15 \%$ deaths were due to sudden cardiac arrest internationally; as many belong to low and middle income countries. Half of the century cardiac arrests occurred out of hospital $\&$ half in hospital but their survival rate was not satisfactory. ${ }^{12}$

Every person should have knowledge and practice of the BLS especially in healthcare setup where full resources are available and healthcare provider should know about the importance and its uniqueness for lifesaving. Nurses being backbone of healthcare setting need to be perfect and expert in BLS skills. ${ }^{13,14}$ The gaps in practice and skills of basic life support in the healthcare system need time-proficient \& less costly options for BLS training.

The objective of this study was to identify effect of interactive computer based and traditional instructor-led based training of basic life support programs on knowledge and skill among nurses.

This is a time to identify the best preparation for the development of BLS expertise in healthcare provider but unfortunately, staffs of the hospital are not easily available to refresh their competency that leads to increase the mortality rate in hospitals.

\section{METHODOLOGY}

Study Design: Cross-sectional study.

Settings: Study was conducted in Lahore School of Nursing (LSN), University of Lahore-Pakistan.

Duration: Period of nine months.

Sampling Technique: Non-probability convenient sampling.

Sample Size: 84 practicing Nurses

Inclusion Criteria: Nurses studying BSN \& MSN actively involved in care of cardiac patients.

Exclusion Criteria: Those having no practice of attending the cardiac patients.

Data Collection Procedure: Groups of participants were nurses studying Bachelor of Science in Nursing (BSN) and Master of Science in Nursing (MSN) actively practicing their work on cardiac patients in different hospitals. Ethical approval was obtained from ERC and written consent was obtained from participants. The two modes of BLS training i.e. Interactive computer-based training program and Traditional instructor-led program were implemented. Data collected through questionnaire among students and practicing nurses before and after implementation of two modes of BLS training.

One group randomly selected was a control group and second group as implemented group. These two modes of training, computer-based program consisting of the dummies practices versus conventional training program were adopted along with a pre-test, to assess knowledge of nurses before training \& posttest to check the retention of knowledge and skills.

BLS Computer based-training program: Under the supervision of faculty member; nurses were allocated BLS CBTraining computerized videos in class with the fixed time. Participants were guided through required equipments. Supervisory staff guided to use / understand the videos.

BLS Traditional Instructor led based-training program: The practicing nurses provided with multimedia program, practicing voice, animated graphics, images and the video with combined way to facilitate the viewers with traditionally covered knowledge in BLS training.

\section{RESULTS}

The first section deals with demographic characteristics \& second shows normality of data while third section of this study deals with differences between pre \& post knowledge regarding basic life support.

Section (I): Concerned with age, gender, educational status and experiences of the participants.

Table 1: Demographic Data of Participants

\begin{tabular}{|c|c|c|c|}
\hline \multicolumn{2}{|c|}{ Variables } & $\begin{array}{c}\text { Computer } \\
\text { Based } \\
\text { Training }\end{array}$ & $\begin{array}{c}\text { Traditional } \\
\text { instructor-based } \\
\text { Training }\end{array}$ \\
\cline { 2 - 4 } & $\begin{array}{c}\text { Frequency } \\
(\%)\end{array}$ & Frequency (\%) \\
\hline \multirow{4}{*}{ Age } & $\begin{array}{c}20-30 \\
\text { years }\end{array}$ & $21(60)$ & $30(88.2)$ \\
\cline { 2 - 4 } & $\begin{array}{c}31-40 \\
\text { years }\end{array}$ & $14(40)$ & $4(11.8)$ \\
\hline \multirow{2}{*}{ Gender } & Male & $5(14.3)$ & $9(26.5)$ \\
\cline { 2 - 4 } Education & Female & $30(85.7)$ & $25(73.5)$ \\
\hline \multirow{2}{*}{ Level } & $\begin{array}{c}\text { BSN/Post } \\
\text { RN }\end{array}$ & $27(77.1)$ & $34(100)$ \\
\cline { 2 - 4 } & MSN & $8(22.9)$ & $0(00)$ \\
\hline \multirow{2}{*}{$\begin{array}{c}\text { Within } 3 \\
\text { years }\end{array}$} & $3(8.6)$ & $15(44.1)$ \\
\cline { 2 - 4 } & $\begin{array}{c}\text { Within } 4 \\
\text { years }\end{array}$ & $11(31.4)$ & $9(26.5)$ \\
\cline { 2 - 4 } & $\begin{array}{c}\text { More than } \\
\text { 5 years }\end{array}$ & $21(60)$ & $10(29.4)$ \\
\hline
\end{tabular}

The age of computer-based training participants were 20-30 years $n=21(60 \%)$ and $31-40$ years $n=14(40 \%)$; similarly, in traditional based training participants age were 20-30years $n=$ 30 (88.2), and 31.40 years $n=4(11.8 \%)$. Gender of computerbased training participants were male $n=5(14.3 \%)$, Female $n=$ $30(85.7 \%)$ but in traditional based training program male were $n=9(26.5 \%)$ and female $n=25(73.5 \%)$. Education level of computer-based training participants were in BSN/Post RN 
$\mathrm{n}=27(77.1 \%)$ and MSN $n=8(22.9)$, in the same way, traditional based training participants were BSN/Post RN $n=34(100 \%)$. In the context of Job experiences of computer-based participants, were within 3years $n=3(8.6 \%)$, within 4 years $n=11(31.4 \%)$ and more than 5 years $n=21(60 \%)$ while in traditional based training the job experience were within 3 years $n=15(44.1 \%)$, within 4 years $n=9(26.5 \%)$ and more than 5 years $n=10(29.4 \%)$.

Section: (II) deal effectiveness of best methodology through knowledge with comparison of computer based training and traditional based training programs.

Table 2: Knowledge assessment tool for basic life support

\begin{tabular}{|c|c|c|c|c|c|}
\hline \multirow{2}{*}{$\begin{array}{l}\text { Sr. } \\
\#\end{array}$} & \multirow{2}{*}{ Question } & \multicolumn{2}{|c|}{ Pre } & \multicolumn{2}{|c|}{ Post } \\
\hline & & CB N (\%) & TM N (\%) & CB N (\%) & TM N (\%) \\
\hline 1 & Correct depth of chest compressions in an adult, & $13(37.1)$ & $8(23.5)$ & $24(68.6)$ & $19(55.9)$ \\
\hline 2 & In the neck injury. What is the correct way to open the airway? & $10(28.6)$ & $16(47.1)$ & $19(54.3)$ & $32(94.1)$ \\
\hline 3 & How long is pulse check last? & $10(28.6)$ & $7(20.6)$ & $22(62.9)$ & $33(94.7)$ \\
\hline 4 & Check for a pulse in an adult? & $11(31.4)$ & $13(37.1)$ & $21(60)$ & $31(91.2)$ \\
\hline 5 & $\begin{array}{l}\text { A child is gasping for breath but has a pulse rate of } 100 \text { per minute. The rescuers } \\
\text { should: }\end{array}$ & $12(34.4)$ & $23(65.7)$ & $19(54.3)$ & $28(82.4)$ \\
\hline 6 & A child is not breathing but has a pulse rate of 50 per minute. The rescuers should: & $15(42.9)$ & $18(52.9)$ & $24(68.6)$ & $31(91.2)$ \\
\hline 7 & $\begin{array}{l}\text { A } 50 \text {-year-old man has been eating steak in restaurant abruptly stands up \& grabs } \\
\text { his neck. The rescuer determines that the victim is choking. The best response is to: }\end{array}$ & $13(37.1)$ & $12(35.3)$ & $21(60)$ & $30(88.2)$ \\
\hline 8 & An infant was choked, becomes unresponsive. The rescuer should: & $3(8.6)$ & $11(32.3)$ & $15(42.9)$ & $30(88.2)$ \\
\hline 9 & Efforts to relieve choking should be stopped when: & $15(42.9)$ & $11(32.3)$ & $18(51.4)$ & $28(82.4)$ \\
\hline 10 & After the AED has delivered the shock, you should... & $12(34.4)$ & $15(42.9)$ & $26(74.3)$ & $30(88.2)$ \\
\hline 11 & $\begin{array}{l}\text { You are giving CPR to } 5 \text {-year old child. A second rescuer comes by and states they } \\
\text { know CPR. What happens to your Compression to Breath ratio when you add } \\
\text { second rescuer? }\end{array}$ & $12(34.4)$ & $12(34.4)$ & $25(71.4)$ & $31(91.2)$ \\
\hline 12 & What is the correct rate of compressions? & $13(37.1)$ & $15(42.9)$ & $25(71.4)$ & $33(94.7)$ \\
\hline 13 & $\begin{array}{l}\text { What is the exact hand position for compressions on the chest of a baby of less than } \\
\text { one year? }\end{array}$ & $19(54.3)$ & $19(54.3)$ & $27(77.1)$ & $33(94.7)$ \\
\hline 14 & What will be your first step if you find a victim \& you are alone? & $14(40)$ & $23(65.7)$ & $25(71.4)$ & $34(100)$ \\
\hline 15 & What is the ratio of compression to breath doing CPR of a young adult person? & $21(60)$ & $19(54.3)$ & $26(74.3)$ & $33(94.7)$ \\
\hline 16 & While CPR of an infant, when you will use both thumbs \& encircled hands? & $9(25.7)$ & $13(37.1)$ & $22(62.9)$ & $33(94.7)$ \\
\hline 17 & What is your next step if you find victim alone \& scene is safe & $16(45.7)$ & $18(51.4)$ & $25(71.4)$ & $31(91.2)$ \\
\hline 18 & $\begin{array}{l}\text { You were alone busy in CPR of adult person \& second rescuer arrives along with } \\
\text { AED \& turns it on. What will be the next step? }\end{array}$ & $25(71.4)$ & $19(54.3)$ & $29(82.9)$ & $33(94.7)$ \\
\hline 19 & $\begin{array}{l}\text { A Youngman of } 48 \text { years lying on the ground. The scene is safe \& you check him for } \\
\text { response. On checking the carotid pulse, he is pulse less and not responding. } \\
\text { You immediately shout for calling } 1122 \& \text { an AED. What will be your next step? }\end{array}$ & $21(60)$ & $19(54.3)$ & $33(94.3)$ & $34(100)$ \\
\hline 20 & Correct sequence of CPR is: & $13(37.1)$ & $18(51.4)$ & $22(62.9)$ & $30(88.2)$ \\
\hline 21 & When performing mouth to mouth breaths on an adult it is important to: & $5(14.3)$ & $8(23.5)$ & $17(48.6)$ & $28(82.4)$ \\
\hline 22 & The bag valve mask is most effective when controlled by & $17(48.6)$ & $12(34.4)$ & $26(74.3)$ & $30(88.2)$ \\
\hline 23 & In two-rescuer CPR situation the person delivering ventilations should be positioned: & $11(31.4)$ & $18(51.4)$ & $24(68.6)$ & $32(94.1)$ \\
\hline 24 & Rescuer CPR is performed at a ratio of what in a child? & $17(48.6)$ & $14(41.2)$ & $23(65.7)$ & $33(94.7)$ \\
\hline 25 & $\begin{array}{l}\text { Which choices best describes the method used to hold mask in place while } \\
\text { delivering ventilations via bag valve mask? }\end{array}$ & $15(42.9)$ & $17(50)$ & $26(74.3)$ & $34(100)$ \\
\hline
\end{tabular}

Assessed Knowledge of participants, through Question \# 1; Correct answers in pre-intervention computer was $n=13(37.1 \%)$ and in traditional based were $n=8(23.5 \%)$ however in the post intervention computer based were $n=24(68.6 \%)$ and traditional based were $n=19(55.9 \%)$. In $Q \# 2$; the pre-result of computer based was $n=10(28.6 \%)$ and traditional $n=16(47.1 \%)$, after intervention effective changes occurred i.e. post computerbased $n=19(54.3 \%)$ and post traditional were 32(94.1\%). Traditional interventions were more effective then computer based. In Q \# 3; the pre- interventions in computer-based results were $n=10(28.6 \%) \&$ traditional were $n=7(20.6 \%)$ but after intervention computer based were $n=22(62.9 \%)$ while traditional based $n=33(94.7 \%)$. In $Q \# 4$; pre-results of both methodology; in computer $n=11(31.4 \%)$ and traditional based $n=13(37.1 \%)$ whereas after intervention; post-result in computer based were $n=21(60 \%)$ and in post-result of traditional were $n=31(91.2 \%)$. In $Q$ \# 5; pre-assessment of computer based were $n=12(34.4 \%)$ and traditional based $n=$ $23(65.7 \%)$ but in post-test computer based were $n=19(54.3)$ and $n=28(82.4 \%)$. It showed that both strategies are effective but traditional based was more effective. In $Q$ \# 6; pre-test of computer based were $n=15(42.9 \%) \&$ traditional based $\mathrm{n}=18(52.9 \%)$ and after intervention; post-test of computer was $n=24(68.6 \%)$ while traditional based were $n=31(91.2 \%)$. It 
showed that traditional based strategy was more effective. In $Q$ \# 7; the pre-test of computer based were $n=13(37.1 \%)$ and traditional based $12(35.3 \%)$ while after intervention the result of post-test of computer based were $n=21(60 \%)$ and traditional based were $30(88.2 \%)$. It indicated that traditional based were more effective than computer based. In Q \# 8; Pre-intervention of computer based were $n=3(8.6 \%)$ and traditional based $n=11$ (32.3\%) but results of post-intervention of computer-based $n=15$ $(42.9 \%)$ \& traditional based $n=30$ (88.2) showing both strategies are effective but traditional based were more effective. $Q \# 9$; pre-scores of computer-based trainings were $n=15(42.9 \%)$ and traditional based $n=11(32.3 \%)$ but after intervention postscores of computer-based were $n=18(51.4 \%)$ and traditional $\mathrm{n}=28(824 \%)$. It meant that both strategies are effective but traditional based were more effective.

In Q: 10; pre-results scores of computer-based were $n=12$ (34.4\%) and traditional were $\mathrm{n}=15(42.9 \%)$ but after intervention the results of computer based were $n=26(74.3 \%)$ and traditional based $n=30(88.2 \%)$ it showed that traditional based was more effective than computer based. In $Q \# 11$; pre-results of computer based were $n=12(34.4 \%)$ and traditional based $\mathrm{n}=12(34.4 \%)$ but after intervention, post-result of computer based were $n=25(71.4 \%)$ \& traditional based $n=31(91.2 \%)$. It also supported the traditional intervention. According to results of $Q \# 12$; pre results of computer were $n=13(37.1 \%)$ and traditional based $n=15(42.9 \%)$ but after intervention in post result of computer were $n=25(71.4 \%)$ and in traditional $n=33$ (94.7\%). In $Q \# 13$; pre-test of the computer-based $n=19$ $(54.3 \%)$ and traditional based $n=19(54.3 \%)$ but in the post test computer-based $\mathrm{n}=27(77.1 \%)$ and traditional based $n=33(94.7 \%)$ showing both strategies effective but traditional based were more effective. In $Q \# 14$; the pre- test of computer based were $n=14(40 \%)$ and traditional based $n=23(65.7 \%)$ but after intervention the post-test of computer $n=25(71.4 \%)$ and traditional based $n=34(100 \%)$ traditional based were highly effective. Results of $Q \# 15$ showed that pre-test of computer based were $n=21(60 \%)$ and traditional based were $n=19$ (54.3\%) but after intervention the post test of computer were $\mathrm{n}=26(74.3 \%)$ and traditional based were $\mathrm{n}=33(94.7 \%)$. It is concluded that both strategies are effective but traditional based were more effective than computer based. Similar findings observed in all remaining questions.

Table 3: Pre-computer \&pre-traditional based training programs result

\begin{tabular}{|c|c|c|c|c|c|}
\hline & Mean & S.D & Range & Minimum & Maximum \\
\hline Pre-Computer & 9.26 & 3.891 & 16 & 3 & 19 \\
\hline Pre traditional & 11.12 & 4.708 & 18 & 1 & 19 \\
\hline
\end{tabular}

The mean pre computer and pre traditional knowledge score was $9.26 \pm 3.891$ and $11 \pm 4.708$, with mean difference, $p$ value $=0.000(<0.05)$
Table 4: Pre-computer \& post-computers mean, standard deviation and range

\begin{tabular}{|c|c|c|c|c|c|}
\hline & Mean & S.D & Range & Minimum & Maximum \\
\hline $\begin{array}{c}\text { Pre- } \\
\text { Computer }\end{array}$ & 9.26 & 3.891 & 16 & 3 & 19 \\
\hline $\begin{array}{c}\text { Post } \\
\text { Computer }\end{array}$ & 20.11 & 5.454 & 20 & 5 & 25 \\
\hline
\end{tabular}

The mean pre computer and post computer knowledge score was $9.26 \pm 3.891$ and $20.11 \pm 5.454$, with mean difference, $p$ value $=0.000(<0.05)$

Table 5: Pre-traditional and post-traditional mean, standard deviation and range

\begin{tabular}{|c|c|c|c|c|c|}
\hline & Mean & S.D & Range & Minimum & Maximum \\
\hline $\begin{array}{c}\text { Pre- } \\
\text { Traditional }\end{array}$ & 11.12 & 4.708 & 18 & 1 & 19 \\
\hline $\begin{array}{c}\text { Post } \\
\text { Traditional }\end{array}$ & 22.76 & 2.216 & 8 & 17 & 25 \\
\hline
\end{tabular}

The mean pre traditional and post traditional knowledge score was $11.12 \pm 4.708$ and $22.76 \pm 2.216$, with mean difference, $p$ value $=0.000(<0.05)$

Table 6: Post-computer \& post-traditional mean, standard deviation and range

\begin{tabular}{|c|c|c|c|c|c|}
\hline & Mean & S. D & Range & Minimum & Maximum \\
\hline $\begin{array}{c}\text { Post } \\
\text { Computer }\end{array}$ & 20.11 & 5.454 & 20 & 5 & 25 \\
\hline $\begin{array}{c}\text { Post } \\
\text { Traditional }\end{array}$ & 22.76 & 2.216 & 8 & 17 & 25 \\
\hline
\end{tabular}

The mean Post computer and post Traditional knowledge score was $20.11 \pm 5.454$ and $22.76 \pm 2.216$, with mean difference, $p$ value $=0.011(<0.05)$

Section (III) deals with comparisons of knowledge and skill.

Table 7: Comparison of Knowledge \& Skills score after 1 week of training in both study groups

\begin{tabular}{|l|c|c|c|c|}
\hline \multirow{2}{*}{} & \multicolumn{4}{|c|}{ Study groups } \\
\cline { 2 - 5 } & \multicolumn{2}{|c|}{ Knowledge } & \multicolumn{2}{c|}{ Skills } \\
\cline { 2 - 5 } & $\begin{array}{c}\text { Post } \\
\text { Computer }\end{array}$ & $\begin{array}{c}\text { Post } \\
\text { Traditional }\end{array}$ & $\begin{array}{c}\text { Post } \\
\text { Comp }\end{array}$ & $\begin{array}{c}\text { Post } \\
\text { Traditional }\end{array}$ \\
\hline Mean & 20.11 & 22.76 & 37.21 & 33.18 \\
\hline S.D & 5.454 & 2.216 & 1.431 & 2.492 \\
\hline Minimum & 5 & 17 & 33 & 28 \\
\hline Maximum & 25 & 25 & 40 & 40 \\
\hline $\begin{array}{l}\mathbf{t} \text { (p- } \\
\text { value) }\end{array}$ & \multicolumn{2}{|c|}{$2.317(<0.05)$} & \multicolumn{3}{|c}{$7.021(<0.001)$} \\
\hline
\end{tabular}


The mean Post computer and post Traditional knowledge score was $20.11 \pm 5.454$ and $22.76 \pm 2.216$, with mean difference, $p$ value $=0.011(<0.05)$. The mean Post computer \& post Traditional skills was score $37.27 \pm 1.431$ and $33.18 \pm 2.492$, with mean difference, $p$-value $=0.000(<0.05)$

\section{DISCUSSION}

The higher number of cardiac arrests occurring every day all over the world and deaths due to cardiac arrest has reached estimated 200,000 every year in Pakistan. ${ }^{11}$ Cardiopulmonary Resuscitation (CPR) has a great importance in frequent human emergencies. Keeping in view the importance of Basic Life Support to reduce the mortality because of sudden cardiac arrest; a randomized trial among practicing nurses was done to compare BLS skills and knowledge between practicing nurses through an interactive computer based and traditional instructorled based programs. ${ }^{12}$

In table-3, the knowledge assessments scale was highly effect to intervention like before the intervention computer based and traditional instructional-led based programs, were having same results like the mean pre computer and pre traditional knowledge score was $9.26 \pm 3.891$ and $11 \pm 4.708$, with mean difference, $p$-value $=0.000(<0.05)$. In the context of literature review, before the intervention all the health worker were have same knowledge in their competency of basic life support which has also be documented in other studies. ${ }^{13-15}$ Most of the health workers had poor knowledge \& skills irrespective of in hospital care and out of hospital care for cardiac arrest patients, being highly sensitive issue to deal the patient care.

In table-4, the mean pre computer and post computer knowledge score was $9.26 \pm 3.891$ and $20.11 \pm 5.454$, with mean difference, $p$-value $=0.000 \quad(<0.05)$ showed that computer-based training programs for BLS were effective for knowledge of learner. In the pre and post comparisons of the knowledge assessed through t-test showed that computerbased training programs were highly significant after interventional results. The way to assess the retention of basic life support knowledge, computer-based training was more effective than traditional instructional led based training programs although other training methods were effective but computer based instructional training were most effective. ${ }^{16}$

In table-5, results of pre-traditional and post-traditional instructional led based training programs, in which the mean pre traditional and post traditional knowledge score was $11.12 \pm$ 4.708 and $22.76 \pm 2.216$, with mean difference, $p$-value $=0.000$ $(<0.05)$ over all the result of computer based training programs were significant compared to second methodology but traditional instructional led based training programs, were very effective for basic life support programs. In this program; learners were confidently applying their knowledge and skills compared to computer-based programs. ${ }^{17,18}$ Learner knowledge could only retained through their job of experience like computer based and traditional based training programs if the participants get recertification of BLS on yearly basis.

In table-6, performance of the participants in both methods of training was almost same, like the mean post-computer \& post- traditional knowledge score was $20.11 \pm 5.454$ and $22.76 \pm$ 2.216, with mean difference, $\mathrm{p}$-value $=0.011(<0.05)$. The mean post-computer and post-traditional skills scored $37.27 \pm 1.431$ and $33.18 \pm 2.492$, with mean difference, $p$-value $=0.000<$ 0.05). During skill evaluation of participants in BLS, computer based training and traditional instructional led based training showed equal but the traditional instructional led based training participants were more confident and skilled compared to computer-based training programs. ${ }^{19-21}$ Significant improvement is documented by researchers in skill performance of nurses after a repeat of BLS. Exercising deliberate practice; majority of nurses achieved adequate competence \& improvement in outcome measures. ${ }^{22-24}$

\section{CONCLUSION}

Basic Life Support is a critical health \& life skill and the training programs achieve high standards of competence. Traditional instructor led based training remarkably improved the proficiency outcome of nurses to recognize \& act in case of sudden cardiac arrest.

\section{SUGGESTIONS / RECOMMENDATIONS}

Training of nurses is necessary to make them perfect and competent in their skills. Further studies are required for usefulness of both approaches in nursing education using different samples. Innovative approaches are needed to develop effective training methods in order to enhance the competence of learners.

\section{CONFLICT OF INTEREST / DISCLOSURE}

Authors have no conflict of interest to be disclosed.

\section{ACKNOWLEDGEMENTS}

The authors are thankful to all the practicing nurses / studying BSN \& MSN courses for their active participation $\&$ timely response to the asked questions.

\section{REFERENCES}

1. Mardegan KJ, Schofield MJ, Murphy GC. Comparison of an interactive $\mathrm{CD}$-based and traditional instructor-led Basic Life Support skills training for nurses. Aust Critical Care. 2015;28(3):160-7.

2. Min MK, Yeom SR, Ryu JH, Kim YI, et al. Comparison between an instructor-led course and training using a voice advisory manikin in initial cardiopulmonary resuscitation skill acquisition. Clin Exp Emerg Med. 2016;3(3):158-64.

3. Benjamin EJ, Blaha MJ, Chiuve SE, et al. Heart disease and stroke statistics-2017 update: a report from the American Heart Association. Circulation. 2017;135(10):146.

4. Perkins GD, Handley AJ, Koster RW, et al. European Resuscitation Council Guidelines for adult basic life support \& automated external defibrillation. Resuscitation.2015;95(2):8199.

5. Partiprajak S, Thongpo P. Retention of basic life support knowledge, self-efficacy \& chest compression performance in Thai undergraduate nursing students. Nurse edu in pract, 2016;16(1):235-41. 
6. Sullivan. An integrative review: Instructional strategies to improve nurses' retention of cardiopulmonary resuscitation priorities. Int J of nursing edu scholarship. 2015;12(1):37-43.

7. Assadi T, Mofidi M, Rezai M et al. The comparison between two methods of basic life support instruction: video self-instruction versus traditional method. Hong Kong Journal of Emerg Med.2015;22(5):291-6.

8. Drummond D, Arnaud C, Thouvenin G, et al. An innovative pedagogic course combining video and simulation to teach medical students about pediatric cardiopulmonary arrest: a prospective controlled study. European journal of pediatrics. 2016;175(6):767-74.

9. Terzi B, Polat Ş, Düzkaya DS. Evaluation of Basic Life Support Training Program Provided for Nurses in University Hosp. Health Sci. 2017;6(6):70-6.

10. Hazinski MF, Nolan JP, Billi JE, et al. Part 1: executive summary: 2010 international consensus on cardiopulmonary resuscitation \& emergency cardiovascular care science with treatment recommendations. Circulation. 2010;122(2):250-75.

11. Ashraf T, Memon MA, Talpur, MS, Panhwar Z, Rasool SI. Frequency of metabolic syndrome in patients with Ischemic Heart Disease. JPMA. 2011; 61(8):729.

12. Razzak JA, Mawani M, Azam I, et al. Burden of out-of-hospital cardiac arrest in Karachi, Pakistan: Estimation through the capture-recapture method. JPMA.2 018;68(7):990-3.

13. Mardegan KJ. Basic Life Support Training for Nurses: Evaluating an Alternative CD-based Approach. La Trobe Univ. 2011.

14. Onan A, et al. The effectiveness of traditional Basic Life Support training and alternative technology-enhanced methods in high schools. Hong Kong J Emerg Med. 2019;26(1):44-52.

15. Lo BM, et al. Comparison of traditional versus high-fidelity simulation in the retention of ACLS knowledge. Resuscitation. 2011;82(11):1440-3.

16. Castillo J. et al. Basic life support \& ext. defibrillation competences after instruction \& at 6 months comparing face-toface $\&$ blended training. Randomized trial. Nurse edu today. 2018;65:232-8.

17. Kim YJ et al. Retention of cardiopulmonary resuscitation skills after hands-only training versus conventional training in novices: a randomized controlled trial. Clinical experi Emerg Medi. 2017;4(2):88.

18. Aebersold M, Tschannen D. Simulation in nursing practice: the impact on patient care. Online J Issues Nurs. 2013;18(2):6.

19. Allen JA, Currey J, Considine J. Annual resuscitation competency assessments: a review of evidence. Aust Crit Care. 2013;26(1):12-7.

20. Alotaibi O, Alamri F, Almufleh L, Alsougi W. Basic life support: Knowledge and attitude among dental students and Staff in the College of Dentistry, King Saud University. The Saudi Journal for Dental Research. 2016;7(1):51-6.

21. Baldi E, Bertaia D, Contri E. School children learn BLS better and in less time than adults. Resuscitation. 2015;88:15-6.

22. Kleinman ME, Brennan EE, Goldberger ZD, et al. Adult basic life support and cardiopulmonary resuscitation quality: 2015 American Heart Association guidelines update for cardiopulmonary resuscitation and emergency cardiovascular care. Circulation. 2015;132(2):414-35.

23. Perkins GD, Handley AJ, Koster RW, et al. European Resuscitation Council Guidelines for adult basic life support \& automated external defibrillation. Resuscitation. 2015;95:81-99.
24. Salunkhe, PA, Dias RA. Effectiveness of demonstration regarding cardiopulmonary resuscitation on knowledge and practice among policemen. IJSR. 2014;3(5):213-9.

\begin{tabular}{|c|c|}
\hline \multicolumn{2}{|c|}{ AUTHORSHIP CONTRIBUTION } \\
\hline $\begin{array}{l}\text { Hajra Sarwar } \\
\text { Lecturer, Department of Nursing, } \\
\text { Lahore School of Nursing, } \\
\text { University of Lahore Pakistan }\end{array}$ & $\begin{array}{l}\text { Study Designed, } \\
\text { Collection / Analysis of data, } \\
\text { Tabulation of Results }\end{array}$ \\
\hline $\begin{array}{l}\text { Sana Sehar } \\
\text { Assistant Professor, Lahore } \\
\text { School of Nursing, University of } \\
\text { Lahore Pakistan }\end{array}$ & $\begin{array}{l}\text { Provided Guidance \& Support } \\
\text { in designing the study, } \\
\text { tabulation of results and } \\
\text { Discussion writing }\end{array}$ \\
\hline $\begin{array}{l}\text { Muhammad Afzal } \\
\text { Associate Professor, Lahore } \\
\text { School of Nursing, University of } \\
\text { Lahore Pakistan }\end{array}$ & $\begin{array}{l}\text { Supervision of study project, } \\
\text { Provided help \& support in writing } \\
\text { the manuscript }\end{array}$ \\
\hline $\begin{array}{l}\text { Dr. Syed Amir Gilani } \\
\text { Professor / Dean faculty of Allied } \\
\text { Health Sciences, } \\
\text { Lahore School of Nursing, } \\
\text { University of Lahore Pakistan }\end{array}$ & $\begin{array}{l}\text { Overall supervision \& guidance in } \\
\text { completion } \\
\text { of the study }\end{array}$ \\
\hline $\begin{array}{l}\text { Dr. Asif Hanif } \\
\text { Associate Professor / Director } \\
\text { Biostatistics, Lahore School of } \\
\text { Nursing, University of Lahore } \\
\text { Pakistan }\end{array}$ & $\begin{array}{l}\text { Guidance \& Help in } \\
\text { designing charts, figures and } \\
\text { Statistical Analysis }\end{array}$ \\
\hline $\begin{array}{l}\text { Dr. Muhammad Mahboob Alam } \\
\text { Associate Professor of Medicine, } \\
\text { Abwa Medical College, } \\
\text { Faisalabad Pakistan }\end{array}$ & $\begin{array}{l}\text { Critical review, } \\
\text { Editing the manuscript, } \\
\text { Final Proof reading }\end{array}$ \\
\hline $\begin{array}{l}\text { Dr. Altaf Pervez Qasim } \\
\text { Professor / Head, Department of } \\
\text { Forensic Medicine, Abwa Medical } \\
\text { College, Faisalabad Pakistan }\end{array}$ & $\begin{array}{l}\text { Literature review, } \\
\text { Authentication of references, } \\
\text { Layout of manuscript }\end{array}$ \\
\hline
\end{tabular}

